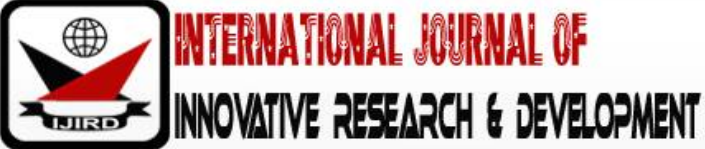

ISSN 2278 - 0211 (Online)

\section{The Regulatory Activity of Aqueous Moringa Oleifera Leaves on Benzene Induced Leukemia in Wister Rats Using TNF- $\alpha$ Assay}

Abutu, Phillip Ogah
Senior Medical Laboratory Scientist, Department of Medical Laboratory,
Paelon Memorial Hospital, Lagos, Nigeria
Dr. Udokwu, Chuka E.
Medical Officer, Department of Clinical, Paelon Memorial Hospital, Lagos, Nigeria
Shaibu, Khadijat Kuburat
Medical Laboratory Scientist, Department of Medical Laboratory,
Health Service Commission, Lagos, Nigeria
Kajero Oluwayemisi Christianah
Medical Laboratory Scientist, Department of Medical Labortory,
Ladoke Akintola University, Nigeria
Benjamin Oluwabukayomi Babatunde
Senior Medical Laboratory Scientist, Department of Haematology,
Clina Lancet Laboratory, Lagos, Nigeria

\section{Abstract:}

Background: Many of the pharmacological principles currently used as anticancer agents were first isolated from plants. Proper understanding of the complex synergistic interaction of various components of anticancer herbs would help in formulating a design to attack the cancerous cells without harming the normal cells of the body.

AIM: This study is aimed at investigating the regulatory activity of aqueous leaves extract of moringa oleifera in leukemic wistar rats using TNF- alpha assay.

MATERIALS AND METHODS: Thirty adult wistar rats were grouped into ten each per group. Intravenous injection of 0.2 $\mathrm{mg} / \mathrm{ml}$ of benzene chromosolv was administered 48 hourly for four weeks. $0.2 \mathrm{ml} \mathrm{of} 100 \mathrm{mg} / \mathrm{ml}$ of aqueous extract of Moringa oleifera was administered orally pre, during and post leukemia induction. Group A (Normal control), Group B (benzene administration only) and Group C (benzene + aqueous Moringa oleifera extract). The plasma samples of each of the groups were collected and analyzed using TNF- $\alpha$ kit by ELISA technique.

RESULTS:A comparison of TNF- $\alpha$ level obtained in all the groups showed that there was no statistically significant difference between them. However, there was mean and standard deviation difference between then. Group B (benzene only) $229.16 \pm 58.18 \mathrm{ng} / \mathrm{L}$, group A (Normal control) $209.04 \pm 18.75 \mathrm{ng} / \mathrm{L}$, group C (treated with AMO) $204.60 \pm 13.54 \mathrm{ng} / \mathrm{L}$. These results imply that in the response of the immune system to leukemia, there is an increased production of TNF- alpha greater than in normal subjects. But at the onset of remission, the TNF-alpha level begins to reduce, hence showing an indication of response to treatment.

CONCLUSION: his study has shown that aqueous extract of Moringa oleifera has anti-leukemic effect thus down regulating TNF-alpha activity as treatment of leukemia sets in.

Keywords: TNF, ELISA, Moringer olifera, wister

\section{Introduction}

The developing world, Africa included, is witnessing an alarming upsurge of cancer incidence. The annual number of new cancer cases is expected to double by 2020 and up to $70 \%$ of the 20 million new cases of cancer predicted to occur yearly will be in the developing world (Jones et al., 1999; Yach et al., 2004). One startling disparity, however, between cancer in the developing and developed worlds is that although the overall incidence of cancer in the developing world is half of that observed in the developed world, survival rates in the developing world are often less than one third of sitespecific cancers in the developed world. This emphasizes the duality of the cancer problem in Africa, for being largely a disease of modern life style, occurring against a background of socio-economic disparities and greater burden of communicable diseases (Sener et al., 2005).

Hundreds of chemicals are capable of inducing cancer in humans or in animals after prolonged or excessive exposure. There are many well-known examples of chemicals that can cause cancer in humans. The fumes of metals, cadmium, nickel, and chromium are known to cause lung cancer. Exposure to arsenic increases the risk of skin and lung 
cancer. Leukemia can result from chemically induced changes in the bone marrow from exposure to benzene among other toxicants (N.T.P, 2011). Benzene is a ubiquitous environmental chemical that causes acute myeloid leukemia (AML), myelodysplastic syndromes (MDS), and probably other hematological cancers, such as non-Hodgkin lymphoma, which includes chronic lymphocytic leukemia (CLL) (Khalade et al., 2010 and Steinmaus et al., 2008). Epidemiological studies have also provided evidence for an association with childhood leukemia (Eden and Smith, 2010). In order to become carcinogenic and cause leukemia, it is understood that benzene must be metabolized to toxic metabolites (Snyder, 2004 and Ross, 2000). The initial metabolic step involves cytochrome P450 (CYP)-dependent oxidation of benzene to benzene oxide, which exists in equilibrium with its tautomer oxepin. Most benzene oxide spontaneously rearranges to phenol (PH), which is either excreted or further metabolized to hydroquinone (HQ), 1,4-benzoquinone (BQ) and 1,2,4-benzetriol (BT). The remaining benzene oxide is either hydrolyzed to produce catechol (CAT) and 1,2-benzoquinone or reacts with glutathione to produce S-phenylmercapturic acid (S-PMA). Metabolism of oxepin is thought to open the aromatic ring, yielding the reactive muconaldehydes and E, E-muconic acid (MA). Human exposures to benzene at air concentrations between 0.1 and $10 \mathrm{ppm}$, result in urinary metabolite profiles with 70-85\% PH, 5-10\% each of HQ, MA and CAT, and less than 1\% of S-PMA (Kim et al., 2006).Benzene oxide, the benzoquinones, muconaldehydes, and benzene diol epoxides (formed from CYP oxidation of benzene dihydrodiol) are electrophiles that readily react with peptides and proteins (Bechtold et al., 1992, Henderson et al., 2005, McDonald et al., 1993 and Waidyanatha et al., 2005)and can thereby interfere with cellular function (Smith, 1996).

The immune system does not only combat foreign antigenic substances but is also vigilant in identifying and eliminating nascent tumor cells. And a special type of immune cells called the T-cells is pivotal sentinel in the immune system's response against cancer (Cancer research institute, 2009). Understanding the mechanisms that control cell proliferation or apoptosis is essential to understanding and controlling diseases, such as acute myeloid leukemia. Monocytes and macrophages, which are derived from myeloid cells, have the ability to proliferate or die dependent on their environment and the controlling signals they encounter (Basu et al., 2007 and Lombardo et al., 2007). One signal that has the capacity to cause either cellular proliferation or cell death in these cells is tumor necrosis factor (TNF). Tumor necrosis factor (TNF)-a is a major effector and regulatory cytokine with a pleiotropic role in the pathogenesis of several immune-regulated diseases and hematologic malignancies, including MDS and AML (Tsimberidou and Giles, 2002). TNF-a stimulates the proliferation of dividing cells, causing hypercellularity or inducing apoptosis in their maturing progeny, which results in pancytopenia (Raza et al., 1996). It is produced by monocytes and T cells but is present in all types of leukemia (Kurzrock et al., 1993). High levels of TNF-a transcripts have been associated with a higher percentage of cells in the S-phase and with resistance to induction therapy (Goa et al., 1998). TNF binds 2 cell-surface receptors, TNFR1 and TNFR2, to regulate multiple cellular actions. Understanding the means by which TNF can control a cell's response has been extensively researched. However, it is still ambiguous as to the mechanism underlying the cell's decision to respond to a stimulus by undergoing cell death, survival, or proliferation (MacEwan, 2002). TNF has been recognized as an activator of nuclear factor-_B (NF- B), a transcription factor implicated in the protection of many cell types, including monocytes and macrophages from apoptosis (Tucker et al., 2004 and Rae et al., 2007) Under physiologic conditions, signaling via TNFR does not lead to monocyte or macrophage cell death because TNF triggers the expression of anti-apoptotic genes through the transcription factor NF- B (Wang et al., 1998). Such genes include Fas-associated protein with death domain-like interleukin-1 (IL-1)-converting enzyme (FLICE/ caspase-8)-inhibitory protein (FLIP) and inhibitor of apoptosis-1. The same cells, however, may become sensitive to cell death signals after the inhibition of NF- B (Liu et al., 2004 and Ma et al., 2005). Furthermore, multiple cell types deficient in mediators of TNF-induced NF- B activation, including p65, inhibitor of NF- B (I B) kinase (IKK)- , and IKK- , are highly sensitive to TNF-induced apoptosis (Liu et al., 1996 and Maeda et al., 2003). Therefore, NF- B activation mediates inhibition of death inducing signals after treatment with TNF and is now considered a target for cancer therapy (Wang et al., 1996 and Karin, 2006). TNF and other inflammatory mediators have been shown to regulate a variety of additional anti-apoptotic genes that are regulated independently of NF- B (Brouard et al., 2000 and Dhakshinamoorthy et al., 2004).

Immunomodulation is required when the host defense mechanism has to be activated under the conditions of impaired immune response or when a selective immunosuppression is desired in situations like autoimmune disorders (Mazumder et al., 1999). In recent years, the immunomodulating properties of plants are being studied extensively with greater interest due to the growing awareness on immune system modulation and to achieve the desirable effects on disease prevention. Several plant remedies well-known in traditional medicine exert their anti-infective effects not only by directly affecting the pathogen, but also by stimulating natural and adaptive defense mechanisms of the host. Therefore plant-remedies have become versatile means with improved immunotherapy (Shruti et al., 2012). Moringa oleiferaLam. (Moringaceae) is one of the 14 species of family Moringaceae, native to India, Africa, Arabia, Southeast Asia, South America, and the Pacific and Caribbean Islands (Iqbal and Bhanger, 2006). Because M. oleifera has been naturalized in many tropic and sub-tropic regions worldwide, the plant is referred to by a number of names such as horseradish tree, drumstick tree, ben oil tree, miracle tree, and "Mother's Best Friend". The Moringa plant has been consumed by humans throughout the century in diverse culinary ways (Iqbal and Bhanger, 2006). Almost all parts of the plant are used culturally for its nutritional value, purported medicinal properties and for taste and flavor as a vegetable and seed. The leaves of M. oleifera can be eaten fresh, cooked, or stored as a dried powder for many months reportedly without any major loss of its nutritional value (Fahey, 2005). Epidemiological studies have indicated that Moleifera leaves are a good source of nutrition and exhibit anti-tumor, anti-inflammatory, anti-ulcer, anti-atherosclerotic and anti-convulsant activities (Chumark et al, 2008). The investigation of the different parts of the plant is multidisciplinary, including but not limited to nutrition, ethnobotany, medicine, analytical chemistry, phytochemistry and anthropology. In India and different parts of Africa, it is cultivated on a large scale in nurseries or orchards. Cultivation entails collection of seeds from the tree, 
development of plantlets in the greenhouse for 2 to 3 months and transplantation of mature stems (1-1.5 m long) to the main fields. The leaves, seeds, flowers, pods (fruit), bark and roots are all seen as a vegetable and each part is uniquely harvested and utilized. For example, fresh leaves are picked, shade dried, ground to a powder, and then stored for later as a food flavoring or additive. Dried or fresh leaves are also used in foods such as soups and porridges (Lockett et al, 2000), curry gravy and in noodles, rice or wheat. Farmers have added the leaves to animal feed to maintain a healthy livestock while utilizing the manure and vegetable compost for crop growth (Fahey, 2005).

The use of chemotherapeutics has some degree of detrimental effects on normal body cells hence resulting in adverse response in patients. They also result in toxic effects that supersede their therapeutic purpose. This has stimulated a rationale on making findings on a possible alternative therapy that won't be of detrimental effect to patients. Thus, the use of medicinal plants extracts and metabolites which are of naturally occurring products and nontoxic. They are used to stimulate the immune system and also exert a direct anti-cancer effect activity on cancer cells in the treatment of cancer. Moringa oleifera is an example of such plants. Studies have shown that the extracts of Moringa oleiferapossess anticancer activity. This study was therefore aimed at investigating the regulatory activity of aqueous Moringa oleifera leaves extract in leukemia using Tumor necrosis factor-alpha analysis.

\section{Materials and Methods}

\subsection{Materials}

Wister rats, Extract from Moringa oleifera, Wooden cages, oral cannular, Hand gloves, K3 EDTA bottles, Needles and syringes, blades, Cotton wool and methylated spirit, Commercial feed and water, Plain bottles, Permanent marker, Measuring cylinder, Whatman filter paper, Distilled water.

\subsection{Reagents}

Distilled water, Benzene-Chromosolv (Leukemic agent) was obtained from sigma, St. Louis, Rat Tumor necrosis factor $\alpha(\mathrm{TNF}-\alpha)$ ELISA Kit (Standard (1280ng/L, Standard diluent, Micro elisa strip plate, Str-HRP-Conjugate Reagent, $30 \times$ wash solution, Biotin-TNF- $\alpha$ Antibody) was obtained from Hangzhou EastBiopharm CO.,LTD, China, K3 EDTA was a product of British Drug house (Pooke, England).

\subsection{Equipments}

The major equipments used in this study are as follows: Weighing balance and Bench centrifuge were products of Lamfied and Gallenkamp, England respectively. Microtitre Plate washer, Automatic Multi-channel Micropipette, Microtitre Plate reader (Hangzhou EastBiopharm CO., LTD, China), ELISA Machine (China).

\section{Methods}

\subsection{Experimental Rats}

Thirty adult wistar rats with an average weight of $150 \mathrm{~g}$ were obtained from the animal house of the college of Health Sciences, Ladoke Akintola University of Technology, Osogbo. The rats were randomly arranged in separate wooden cages each containing 10 wistar in a group. They were allowed to acclimatize for a period of seven days before the commencement of the experiment. The animals were maintained at room temperature $28^{\circ} \mathrm{C}( \pm 2)$ with 12 hours light/ dark cycle and also allowed unrestricted access to water and rat feed.

\subsection{Production of Aqueous Extract of Moringa Oleifera Leaves}

The fresh leaves Moringa oleifera were collected from Osogbo local government area of Osun State. It was identified at the department of Botany, Obafemi Awolowo University, Ile-Ife, Nigeria. Thereafter authenticated by the Department of pharmacognosis, Obafemi Awolowo University, Ile-Ife, Osun State. The extraction process began by the drying of the fresh leaves at room temperature over a period of three weeks. The dried leaves were then grinded into fine powder using an electric blender. The fine powder was then weighed and then soaked with measured quantity of distilled water (for every $10 \mathrm{ml}$ of distilled water, $1 \mathrm{~g}$ of Moringa oleifera powder). The mixture was stirred with the aid of a stirrer and left for 48 hours. Thereafter it was filtered using filter papers in order to collect the filtrate from the mixture. The volume of the filtrate was measured and evaporated to dryness at temperature $45^{\circ} \mathrm{C}$ with the use of petri dish placed in oven for the collection of the plant extract. The eventual residue was carefully scrapped, weighed and refrigerated until further analysis was carried out.

\subsection{Preparation of Aqueous Extract of Moringa Oleifera Leaves}

Weight of the empty nylon $=10.1 \mathrm{~g}$

Weight of nylon with Moringa oleifera leaves $=440.5 \mathrm{~g}$

Weight of Moringa oleifera leaves $=430.4 \mathrm{~g}$

Weight of empty bottle $=359.2 \mathrm{~g}$

Weight of empty bottle with grinded Moringa oleifera leaves $=785.6 \mathrm{~g}$

Weight of grinded Moringa oleifera leaves $=426.4 \mathrm{~g}$

The grinded Moringa oleifera leaves were kept in a clean bottle and mixed with water in ratio 1:10 for extraction $(4000 \mathrm{ml}$ of distilled water to $400 \mathrm{~g}$ of Moringa oleifera leave powder). The mixture was left for 48 hours, but was stirred at intervals for proper extraction. Using whatman filter paper, the mixture was filtered in order to obtain filtrate from the mixture. The 
volume of the filtrate was $3089 \mathrm{ml}$ and the weight of the residue was $370.5 \mathrm{~g}$. The filtrate was poured into Petri dishes to evaporate to dryness at temperature of $40^{\circ} \mathrm{C}$ in oven for the collection of the plant extract.

Weight of the empty universal bottle $=10.7 \mathrm{~g}$

Weight of the dried aqueous extract with bottle $=55.9 \mathrm{~g}$

Weight of dried aqueous extract $=45.2 \mathrm{~g}$

3.4. LD50 of the plant extract.

The lethal dose of $1585 \mathrm{mg} / \mathrm{kg}$ was adopted according to Awodele et al., 2012

\section{Calculation of the Plant Extract Administered}

One gram of the extract was weighed and was dissolved into $10 \mathrm{ml}$ of distilled water which gives the stock/ working solution; 1 in 10 of lethal dose is normal dose

$$
\begin{gathered}
\text { Administered volume }=\frac{\text { normal dose } \mathrm{x}}{1000} \frac{\text { body weight }}{\text { stock solution }} \\
=\quad 158.5 \times 150 \\
=0.2 \mathrm{ml} \text { of } 100 \mathrm{mg} / \mathrm{ml} \text { of aqueous extract of Moringa oleifera leaves. }
\end{gathered}
$$

\subsection{Administration of Plant Extract}

The aqueous extract of Moringa oleifera was administered by gavage once daily. With the aid of oral cannular of $0.2 \mathrm{ml}$ of $100 \mathrm{mg} / \mathrm{ml}$ was administered to the rats over a period of 4 weeks.

\subsection{Administration of the Benzene chromosolv}

Benzene chromosolv, a product of Sigma-Aldrich with Cat No 270709 and $\geq 99.9 \%$ was diluted in water for injection at a concentration of $1 \mathrm{ml}$ of the benene chromosolv to $9 \mathrm{ml}$ of water for injection. Exactly $0.2 \mathrm{ml}$ was administered through the vein at the tail 48 hourly for 4 weeks.

\subsection{Experimental Protocol}

- GROUP A: diet only (Normal control)

- GROUP B: Administration of benzene for 4 weeks and sacrificed thereafter.

- GROUP C: Administration of benzene + aqueous extract of Moringa oleifera (regulatory activity).

\subsection{Plasma Sample Collection}

After eight weeks of the experiment, the animals were sacrificed by cervical dislocation and blood samples were collected via heart puncture into EDTA bottles and labeled according to the groups. Plasma for each group was obtained by centrifuging blood samples at $2000 \mathrm{rpm}$ for 5 minutes. The plasma samples were then refrigerated until the day of analysis.

\subsection{TNF Analysis using Rat TNF- $\alpha$ ELISA kit}

\subsubsection{Principle}

The kit uses a double antibody sandwich enzyme linked immunosor bent assay (ELISA) to assay the level of Rat Tumor necrosis factor $\alpha$ (TNF- $\alpha$ ) in samples. Addition of Tumor necrosis factor $\alpha$ (TNF- $\alpha$ ) to monoclonal antibody enzyme well which was pre-coated with Rat Tumor necrosis factor $\alpha$ (TNF- $\alpha$ ) monoclonal antibody was done, incubated, then the addition of Tumor necrosis factor $\alpha$ (TNF- $\alpha$ ) antibodies labeled with biotin, and combined with streptavidin-HRP to form immune complex, further incubation was carried out and washing again to remove the uncombined enzyme. Upon the addition of Chromogen solution, A, B, the color of the liquid changed to blue, and at the effect of an acid, the color finally became yellow. The chroma of colour and concentration of the Rat substance Tumor necrosis factor $\alpha$ (TNF- $\alpha$ ) of samples were positively correlated.

\subsubsection{Assay Procedure}

- A total of six standard dilutions were made using the protocol table below

- Standard well: It was run in duplicates making a total of twelve wells which contains $50 \mu l$ of standard solution and $50 \mu \mathrm{l}$ of Streptavid in-HRP.

- Blank well: Blank well was made by adding nothing to the well.

- Sample well: Samples well were made by adding $40 \mu \mathrm{l}$ of the test sample followed by then addition of $10 \mu \mathrm{l}$ of Biotin (TNF- $\alpha$ antibody) and $50 \mu$ l of streptavid in-HRP.

- The wells were shaking gently after being sealed by a membrane seal and incubated for 60 minutes at $37^{\circ} \mathrm{C}$.

- Confection: A wash solution was prepared by diluting 30 times the $30 \times$ washing concentrate with distilled water.

- Washing: The membrane was removed carefully, the liquid drained and the remaining water was shaken away. The wells were washed five times using the wash solution prepared to remove unbound antibody.

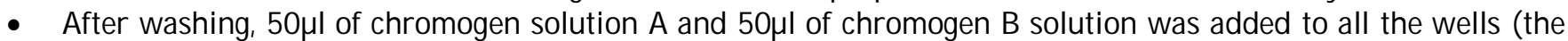
colour of the liquid changes to blue), gently mixed and incubated for 10 minutes at $37^{\circ} \mathrm{C}$ away from light. 
- Stop: 50pl of stop solution was added into each well to stop the reaction (the blue changes into yellow immediately).

- Final measurement: The optical density (OD) was measured under $450 \mathrm{~nm}$ wavelength and was carried out within 15 minutes after adding the stop solution.

\begin{tabular}{|c|c|c|c|}
\hline S/ N & Concentration & Standard no & Dilutions \\
\hline 1 & $640 \mathrm{ng} / \mathrm{L}$ & 5 & $120 \mu \mathrm{l}$ Original Standard +120 $\mu \mathrm{l}$ Standard diluents \\
2 & $320 \mathrm{ng} / \mathrm{L}$ & 4 & $120 \mu \mathrm{l}$ Standard No. $5+120 \mu \mathrm{l}$ Standard Diluents \\
3 & $160 \mathrm{ng} / \mathrm{L}$ & 3 & $120 \mu \mathrm{l}$ Standard No. $4+120 \mu \mathrm{l}$ Standard Diluents \\
4 & $80 \mathrm{ng} / \mathrm{L}$ & 2 & $120 \mu \mathrm{\mu l}$ Standard No. 3 $+120 \mu \mathrm{l}$ Standard Diluents \\
5 & $40 \mathrm{ng} / \mathrm{L}$ & 1 & $120 \mu \mathrm{\mu l}$ Standard No. $2+120 \mu \mathrm{l}$ Standard Diluents \\
6 & $0 \mathrm{ng} / \mathrm{L}$ & 0 & $120 \mu \mathrm{ll}$ Standard Diluents only \\
\hline
\end{tabular}

Table 1: Dilution Protocol

\section{Statistical Analysis Method}

Statistical analysis was performed using SPSS version 15 with the following statistical tools: mean, standard deviation, one-way variance analysis (ANOVA) and $\mathrm{p}$-value. Differences at $\mathrm{p} \varangle 0.05$ were considered to be statistically significant and the experimental values are as mean \pm standard deviation by Thamhane's post hoc test.

\section{Results}

The yield of extraction process for aqueous extract of Moringa oleifera leaves and the effect of benzene and aqueous extract of Moringa oleifera on TNF-alpha levels in various experimental groups are shown in the figure.

\subsection{Yield of Aqueous Moringa oleifera Leaves Extraction}

The result of the extraction process of the plant extract is as follows; $100 \mathrm{~g}$ of the dry powder of Moringa oleifera was soaked in 1 litre of aqueous and after proper sieving and drying, $11.3 \mathrm{~g}$ of dry residue was obtained.

\subsection{Effect of Benzene and Aqueous Extract of Moringa Oleifera on Tnf-Alpha Levels}

The results of the Tumor necrosis factor (TNF) - $\alpha$ level in the various experimental groups are shown in the figure below. The group induced with leukemia without treatment showed an increased TNF - $\alpha$ level was observed when compared with other groups. Figure 1 contains comparison of Group A which contained normal Wister rats fed with rat chow and water and served as the normal control, Group B treated with benzene for the induction of leukemia and Group $\mathrm{C}$ treated with benzene and then aqueous Moringa oleifera. No statistically significant difference $(\mathrm{P}>0.05)$ was observed between the groups, however there is a mean \pm standard deviation difference in TNF - $\alpha$ production levels between them. Higher TNF - $\alpha$ level was seen in group B induced with leukemia without treatment greater than the group induced with leukemia and then treated with aqueous Moringa oleifera and normal control group.

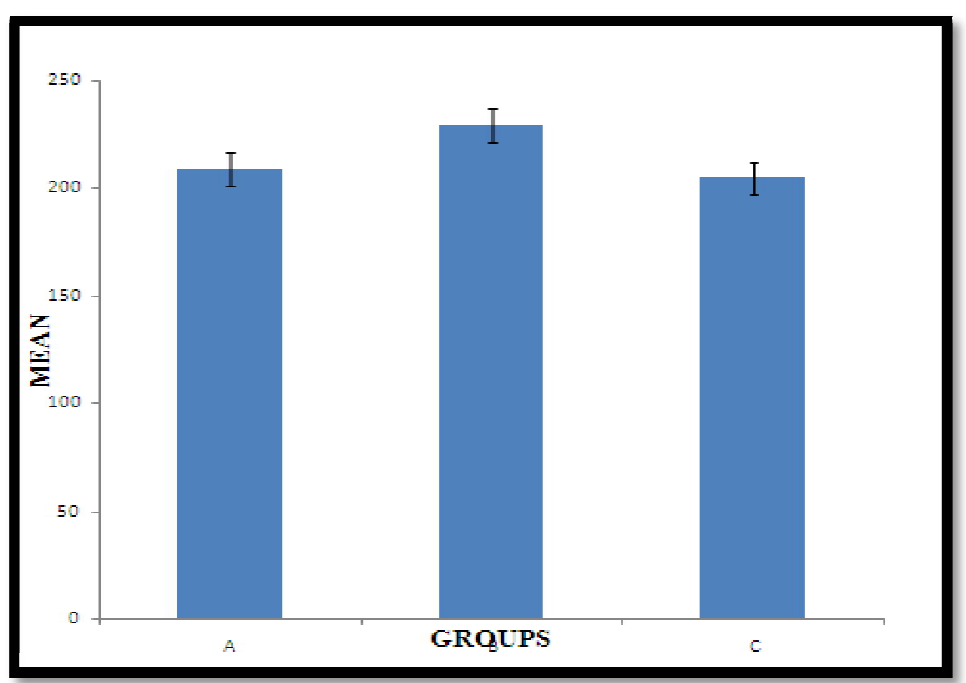

Figure 1: Bar Chart Showing Comparison of TNF-Alpha Level in

Experimental Group

Error Bar $\pm 1 \mathrm{SD}$

Key: S.D; Standard deviation

GROUP A; Normal control

GROUP B; leukemia control

GROUP C; Treatment group 


\section{Discussion and Conclusion}

The developing world, Africa included, is witnessing an alarming upsurge of cancer incidence. The annual number of new cancer cases is expected to double by 2020 and up to $70 \%$ of the 20 million new cases of cancer predicted to occur yearly will be in the developing world (Jones et al., 1999; Yach et al., 2004).

This study investigated the regulatory effect of aqueous extract of Moringa oleifera in leukemic wistar rats using TNF- $\alpha$ assay.Benzene has been established to be a known carcinogenic substance that causes various forms of cancers, notably Acute Myeloid leukemia (AML), especially due to occupational hazards (Hayes et al., 2001). Leukemia was induced by the administration of $0.2 \mathrm{mg} / \mathrm{ml}$ of benzene chromosolv 48 hourly for four weeks. The induction of leukemia was established by the estimation of a known tumor marker called Beta-2-Microglobulin (B2M). B2M level estimated in the various experimental groups, showed that there was marked increase in B2M level in the group of rats that were induced with leukemia without any treatment compared with the normal control group and those induced with leukemia but treated with aqueous extract of Moringa oleifera (Data not shown). This finding established the induction of Leukemia using benzene chromosolv. This result correlates with Campos et al., 1984 in which B2M level was found to be elevated above normal in acute myeloid leukemia patients.

In this study, the results obtained showed that there was no statistically significant difference between the various groups of treatment. However, slight difference between their mean and standard deviation was observed. When the result of TNF- $\alpha$ level obtained in Normal control, leukemic control and AMO treatment group were compared; there was no statistically significant difference between them. However, there was mean \pm standard deviation difference between then. Leukemic group had TNF- $\alpha$ level of $229.16 \pm 58.18 \mathrm{ng} / \mathrm{L}$; Normal control had 209.04 $\pm 18.75 \mathrm{ng} / \mathrm{L}$, AMO treatment group with $204.60 \pm 13.54 \mathrm{ng} / \mathrm{L}$. These results imply that in the response of the immune system to leukemia, there is an increased production of TNF- alpha greater than in normal subjects. But at the onset of remission, the TNF-alpha level begins to reduce, tending towards the normal TNF-alpha mark.The result obtained is similar to those observed when the changes and significance of tumor necrosis factor alpha (TNF $\alpha$ ) in the serum and cerebrospinal fluid (CSF) of children with acute lymphoblastic leukemia (ALL) and acute myeloid leukemia (AML) that was evaluated by Yu et al in 2003. According to Barak et al in 1999, decrease in TNF-alpha levels is indicative of the response of the subject to treatment while an increase in TNF- alpha levels accompanies active disease (Barak et al., 1999). Thus, the anti-tumor properties of Moringa oleifera are responsible for the treatment of leukemia resulting in the down regulation of tumor necrosis factoralpha activity. This result conforms to the work done by Khalafalla et al in 2009, were the active principle from Moringa oleifera leaves effective against two leukemias and a Hepatocarcinoma was investigated. They concluded that Moringa oleifera has the potential for use as source of natural treatment of diseases such as cancer (Khalafalla et al., 2009).

In conclusion, this study has shown that aqueous extract of Moringa oleifera has anti-leukemic effect thus down regulating TNF-alpha activity as treatment of leukemia sets in.

\section{References}

i. Brouard, S., Otterbein, L.E. and Anrather, J. (2000). Carbon monoxide generated by heme oxygenase 1 suppresses endothelial cell apoptosis. J Exp Med.192:1015-1025.

ii. Burridge, E. (2007). Chemical Profile: Benzene. ICIS Chemical Business (Europe/ Middle East/ Asia), 2(57): 36

iii. Campos, L., Vu Van, H., Ville, D., Imbert, C., Gentilhomme, Y., Luo, C., Fiere, D. and Viala, J.J. (1984). Serum beta-2 microglobulin in adult myeloid acute leukemia. Annals of hematology. 48(4):221-226.

iv. Cancer research institute. (2009)

v. Chumark, P., Khunawat, P., Sanvarinda, Y., Phornchirasilp, S., Morales, N.P, Phivthongngam, L., Ratanachamnong, P., Srisawat, S. and Pongrapeeporn KS (2008). The in vitro and exvivo antioxidant properties, hypolipidaemic and antiatherosclerotic activities of water extract of Moringa oleifera Lam Leaves. J. Ethnopharmacol. 116: 439-446

vi. Dhakshinamoorthy, S. and Porter, A.G. (2004). Nitric oxide induced transcriptional up-regulation of protective genes by Nrf2 via the antioxidant response element counteracts apoptosis of neuroblastoma cells. J Biol Chem.279:20096-20107.

vii. Hayes, R.B., Songnian, Y., Dosemeci, M. and Linet, M. (2001). Benzene and lymphohematopoietic malignancies in humans. Am J Ind. Med. 40:117-26.

viii. Iqbal, S. and Bhanger M.I, (2006). Effect of season and production location on antioxidant activity of Moringa oleifera leaves grown in Pakistan.J. Food Compos. Anal. 19: 544-55.

ix. Jones, S.B. (1999). Cancer in the developing world: a call to action. BMJ. 21:319(7208):505-8.

x. Khalafalla, M.M., Abdellatef, E., Daffalla, H.M., Nassrallah, A.A., Aboul-Enein, K.M., Lightfoot, D.A., Cocchetto, A. and El-Shemy, H.A. (2009). Antileukemia activity from root cultures of Vernonia amygdalina. Journal of Medicinal Plants Research. 3(8): 556-562

xi. $\quad$ Kim, S., Vermeulen, R., Waidyanatha, S., Johnson, B.A., Lan, Q., Smith, M.T., Zhang, L., Li, G., Shen, M., Yin, S., Rothman, N. and Rappaport, S.M. (2006). Modeling human metabolism of benzene following occupational and environmental exposures. Cancer Epidemiol. Biomarkers Prev. 15 (11): 2246-2252.

xii. Kurzrock, R., Kantarjian, H. and Wetzle, r M. (1993). Ubiquitous expression of cytokines in diverse leukemias of lymphoid and myeloid lineage. Exp Hematol. 21:80-85.

xiii. Liu, H.T., Ma, Y.Y. and Pagliari, L.J. (2004). TNF-induced apoptosis of macrophages following inhibition of NF- B: a central role for disruption of mitochondria.J Immunol; 172:1907-1915.

xiv. Liu, Z.G., Hsu, H.L., Goeddel, D.V. and Karin, M. (1996). Dissection of TNF receptor 1 effector functions: JNK activation is not linked to apoptosis while NF B activation prevents cell death. Cell; 87:565-576. 
xv. Lombardo, E., Alvarez-Barrientos, A., Maroto, B., Bosca, L. and Knaus, U.G. (2007) TLR4-mediated survival of macrophages is MyD88 dependent and requires TNF- autocrine signalling.J Immunol.178:3731-3739.

xvi. McDonald, T.A., Waidyanatha, S. and Rappaport, S.M. (1993). Production of benzoquinone adducts with hemoglobin and bone-marrow proteins following administration of [13C6] benzene to rats. Carcinogenesis14(9): 1921-1925.

xvii. NTP (1986). NTP toxicology and carcinogenesis studies of benzene in F344/N rats and B6C3F1 mice (Gavage studies). Natl Toxicol ProgramTech Rep Ser. 289: 1-277.

xviii. NTP (2005). Benzene NTP 11th Report on Carcinogens. Rep Carcinog. 11: 1-A32.

xix. Rae, C., Langa, S., Tucker, S.J., MacEwan, D.J. (2007). Elevated NF-B responses and FLIP levels in leukemic but not normal lymphocytes: reduction by salicylate allows TNF-induced apoptosis. Proc. Natl. Acad. Sci. U.S.A.104:1279012795.

xx. Smith, M.T. (1996). The mechanism of benzene-induced leukemia: a hypothesis and speculations on the causes of leukemia. Environ. Health Perspect.104 (6):1219-1225.

xxi. Snyder, C.A., Goldstein, B.D. and Sellakumar, A.R.(1980). The inhalation toxicology of benzene: incidence of hematopoietic neoplasms and hematotoxicity in ARK/ J and C57BL/6J mice. Toxicol Appl Pharmacol. 54: 323-331.

xxii. Snyder, C.A., Sellakumar, A.R., James, D.J. and Albert, R.E. (1988). The carcinogenicity of discontinuous inhaled benzene exposures in CD-1 and C57Bl/ 6 mice. Arch Toxicol. 62:331-335

xxiii. Snyder, R. (2004). Xenobiotic metabolism and the mechanism(s) of benzene toxicity, Drug Metab. Rev. 36 (3-4): 531-547.

xxiv. Tucker, S.J., Rae, C., Littlejohn, A.F., Paul A. and Mac- Ewan, D.J. (2004). Switching leukemia cell phenotype between life and death. Proc. Natl. Acad. Sci. U.S.A.101:12940-12945.

xxv. Waidyanatha, S. and Rappaport, S.M. (2005). Investigation of cysteinyl protein adducts of benzene diolepoxide, Chem. Biol. Interact. 153:261-266.

xxvi. Wang, C.Y., Mayo, M.W. and Baldwin, A.S. (1996). TNF- and cancer therapy-induced apoptosis: potentiation by inhibition of NF- B. Science.274:784-787.

xxvii. Wang, C.Y., Mayo, M.W., Korneluk, R.G., Goeddel, D.V. and Baldwin, A.S. (1998). NF-B antiapoptosis: induction of TRAF1 and TRAF2 and c-IAP1 and c-IAP2 to suppress caspase-8 activation. Science.281:1680-1683.

xxviii. Yach, D., Hawkes, C., Gould, C.L. and Hofman, K.J. (2004). The global burden of chronic diseases: Overcoming impediments to prevention and control.JAMA. 2;291 (21):2616-22. 